\title{
Letter referencing "Randomized open-label phase II trial of 5-day aprepitant plus ondansetron compared to ondansetron alone in the prevention of chemotherapy-induced nausea-vomiting in glioma patients receiving adjuvant temozolomide"
}

\author{
Kayoko Morio $^{1}$ (D) Jun Watanabe ${ }^{2} \cdot$ Yasushi Tsujimoto $^{3}$ \\ Received: 25 April 2020 / Accepted: 14 May 2020 / Published online: 27 May 2020 \\ (C) Springer-Verlag GmbH Germany, part of Springer Nature 2020
}

To the editor:

We read the prospective, open-label, randomized trial reported by Patel et al. [1] with great interest and appreciate their effort in clarifying the chemotherapy-induced nauseavomiting (CINV) efficacy of aprepitant plus ondansetron in patients receiving adjuvant temozolomide. However, we would like to mention three concerns regarding this study.

First, the authors should report the number of participants with steroid use and the dose of steroids in each group. They have only reported that steroid was strongly associated with complete control. It is important to demonstrate whether such strong prognostic factors were balanced in both arms [2].

Second, they did not report one of the prespecified outcomes, i.e., the time to treatment failure, in the trial protocol (NCT01450826). Such selection of reporting outcome can introduce bias [3].

Finally, there was a spin in the conclusion of the abstract. The authors concluded that aprepitant plus ondansetron may be beneficial concerning the effect of CINV on the quality of life (QoL) of patients. However, there was no significant difference between arm A and arm B in terms of QoL for all

Kayoko Morio

kayoko.morio0826@gmail.com

1 Department of Pharmacy, Kobe University Hospital, 7-5-2, Kusunoki-cho, Chuo-ku, Kobe 650-0017, Japan

2 Department of Internal medicine, Iwami Hospital, 1029-2 Uradome Iwami, Tottori 681-0003, Japan

3 Department of Nephrology and Dialysis, Kyoritsu Hospital, Chuo-cho 16-5, Kawanishi 666-0016, Japan days. Claiming efficacy without considering the statistically nonsignificant primary outcome or reporting statistically nonsignificant results as beneficial can be regarded as a spin [4].

\section{Compliance with ethical standards}

Conflict of interest The authors declare that they have no conflict of interest.

\section{References}

1. Patel MP, Woodring S, Randazzo DM, Friedman HS, Desjardins A, Healy P, Herndon JE, McSherry F, Lipp ES, Miller E, Peters KB, Affronti ML (2020) Randomized open-label phase II trial of 5-day aprepitant plus ondansetron compared to ondansetron alone in the prevention of chemotherapy-induced nausea-vomiting (CINV) in glioma patients receiving adjuvant temozolomide. Support Care Cancer 28(5):2229-2238. https://doi.org/10.1007/s00520-01905039-x

2. Moher D, Hopewell S, Schulz KF, Montori V, G $\varphi$ tzsche PC, Devereaux PJ, Elbourne D, Egger M, Altman DG (2010) CONSORT 2010 Explanation and Elaboration: updated guidelines for reporting parallel group randomised trials. BMJ 340:c869. https://doi.org/10.1136/bmj.c869

3. Kirkham JJ, Dwan KM, Altman DG, Gamble C, Dodd S, Smyth R, Williamson PR (2010) The impact of outcome reporting bias in randomised controlled trials on a cohort of systematic reviews. BMJ 340:c365. https://doi.org/10.1136/bmj.c365

4. Boutron I, Dutton S, Ravaud P, Altman DG (2010) Reporting and interpretation of randomized controlled trials with statistically nonsignificant results for primary outcomes. JAMA 303(20):20582064. https://doi.org/10.1001/jama.2010.651

Publisher's note Springer Nature remains neutral with regard to jurisdictional claims in published maps and institutional affiliations. 